\title{
De la sorpresa a la incertidumbre: abriendo etapas en el estudio de la temática sobre género y migración en el contexto español
}

\author{
Laura Oso \\ Natalia Ribas-Mateos \\ Universidad de A Coruña. Facultad de Sociología \\ osofac@udc.es; nribas@udc.es
}

\section{Sumario}

1. De la crisis de la reproducción social a la crisis del capitalismo global

2. De la trabajadora inmigrante invisible a la familia transnacional como unidad de análisis
Agradecimientos

Referencias bibliográficas

Desde que, en los años ochenta, España empieza a constituirse en un país de inmigración, las mujeres han tenido un papel determinante en la configuración de los flujos de entrada y de las comunidades asentadas, no sólo en lo que se refiere a su representación numérica, sino en tanto agentes económicos y sociales. Ya en los años noventa, los primeros trabajos que abordaron la inmigración femenina en este país apuntaron en esta línea, sacando a la luz el rol de las mujeres inmigrantes como pioneras de las cadenas migratorias, en el contexto del surgimiento de flujos migratorios feminizados por nacionalidad en el sur de Europa. Entre los primeros trabajos, destacaron las monografías por nacionalidad (Gregorio, 1998; Ramírez, 1998; Ribas, 1999), así como los análisis sobre la inserción laboral de las mujeres inmigrantes, principalmente en el sector del servicio doméstico (Colectivo IOÉ, 2001; Escrivá, 2003; Herranz, 1996; Oso, 1998; Parella, 2003; Solé, 1994). Investigaciones que coincidieron en sacar a la luz cómo estos movimientos poblacionales ya no reproducían el estereotipo de la mujer reagrupada. 
En los últimos años, ha variado, en gran medida, la intensidad, así como el "color», de las migraciones femeninas en España. Nuevos rostros asoman en el mapa multicultural del Estado español. Con el cambio de siglo, otras sonrisas con voz femenina protagonizan, en el nuevo contexto económico y social, junto a las miradas más antiguas, las nuevas "problemáticas migratorias». Emergen voces del Este de Europa, de países andinos. Salen a la luz otros nichos de empleo (empresariado étnico, agricultura) y, desde la producción científica, se abordan, entre otros, nuevos interrogantes sobre la maternidad transnacional, la familia, la ciudadanía, la participación política de las mujeres, las migraciones por amor, etc.

En el año 2000, se publicó en la revista PAPERS un monográfico titulado «Inmigración femenina en el Sur de Europa» (Papers: Revista de Sociología, ISSN 0210-2862, n 60), que fue editado por Natalia Ribas. Algo más de diez años después, hemos querido revivir la temática de género y migración volviendo a editar un nuevo monográfico en esta misma revista que dé cuenta de las transformaciones acontecidas tras una década de inmigración femenina en nuestro país y que abra un espacio de debate para plantear las líneas de investigación actuales, reflexionando sobre los nuevos marcos e interrogantes teóricos.

La publicación actual recopila las ponencias (Carmen Gregorio, Claudia Pedone, Belén Agrela, Sandra Gil, Estrella Gualda, Jordi Roca, Yolanda Bodoque y Montserrat Soronellas) que se presentaron en la sesión temática titulada "Género y migraciones», del VI Congreso sobre las Migraciones en España (A Coruña, 17-19 de septiembre de 2009) y que fue coordinada por Dolores Juliano y Laura Oso. Encuentro de carácter bianual que constituye un referente académico y social en el estudio de las migraciones en nuestro país. También saca a la luz contribuciones de algunos miembros del comité científico de dicha sesión (Dolores Juliano, Sonia Parella), así como la aportación de dos textos de autoras que han sido invitadas a participar en el monográfico (Amelia Sáiz y María Villares), puesto que sus investigaciones temáticas constituían, a nuestro modo de ver, un complemento clave para el resto de las tratadas en el monográfico (inmigración de mujeres chinas y empresariado étnico).

Para elaborar esta introducción, hemos partido del monográfico publicado en el año 2000 y hemos intentado analizar cómo ha ido cambiando la inmigración femenina en el marco del contexto migratorio español. Lo hemos hecho sacando a la luz cómo han ido variando los interrogantes académicos y las líneas de investigación en algo más de una década. Dos son las transformaciones principales en el abordaje de la temática sobre género y migración que hemos identificado y que guiarán el hilo conductor de nuestra introducción:

1. La primera está relacionada con el contexto socioeconómico. Si, en el año 2000, la producción científica se centraba en analizar la inmigración femenina en el marco de la "crisis de la reproducción social», la publicación actual vuelca su mirada hacia la "crisis del capitalismo global».

2. En segundo lugar, si, hace algo más de una década, la literatura académica se interesaba, sobre todo, por sacar de la invisibilidad a la figura de la tra- 
bajadora inmigrante, en la actualidad, el interés se centra más bien en el estudio de la familia transnacional.

Pero veamos con más detalle cómo se han ido configurando estas transformaciones en el abordaje de la problemática sobre género y migración en España. Lo haremos comparando las temáticas que se trataron en el monográfico del año 2000 con las que se presentan en la publicación actual.

\section{De la crisis de la reproducción social a la crisis del capitalismo global}

Hace algo más de una década, en esta misma revista, se abordaba la temática sobre género y migración tomando como referencia el contexto del cambio social acaecido en la Europa del Sur, especialmente en relación con las transformaciones socioeconómicas vinculadas al postfordismo y el replanteamiento del Estado de bienestar. En esta etapa, muchos estudios intentaban sobrepasar la aproximación neoclásica de las migraciones, fundamentada en los modelos de expulsión y atracción (push-pull) e inspirada por el enfoque clásico del Homo economicus, que reconoce principalmente la conducta competitiva y acumulativa de los individuos ${ }^{1}$. Desde esta perspectiva, la figura protagonista de los movimientos poblacionales era el migrante varón y se invisibilizaba la presencia y el rol activo como mano de obra de las mujeres en las migraciones internacionales.

En este contexto, surgieron voces de muchas autoras que pusieron el énfasis en sacar a la luz la relevancia, tanto cuantitativa como en tanto a su aportación como mano de obra, de los flujos migratorios feminizados. A nivel microeconómico, King y Zontini (2000) distinguían entonces dos tipos de nichos laborales para las mujeres inmigrantes en la Europa del Sur: el servicio doméstico y el trabajo sexual. El análisis de la presencia de mujeres inmigrantes nos ofrecía una imagen de las estructuras patriarcales subyacentes en el sur de Europa. Esta migración se abordó, en su día, desde el papel que tenían las mujeres inmigrantes en las posiciones laborales feminizadas, que, además de desvalorizadas, estaban vinculadas a tareas de asistencia y servicios.

El monográfico publicado en el año 2000 sacaba a la luz cómo las mujeres trabajadoras en el servicio doméstico liberaban a las mujeres autóctonas del trabajo reproductivo del hogar, para que pudiesen producir en otros lugares fuera de la casa, debido, entre otras razones, a las cambiantes necesidades de consumo y de estilo de vida de las familias de clase media baja españolas. Esta función se concebía, por un lado, desde el incremento de la tasa de actividad laboral de las mujeres casadas de las clases medias urbanas y, por otro, desde la reproducción de la servidumbre como símbolo de estatus.

Durante los años noventa, según Catarino y Oso (2000), lejos de asistir a la muerte del servicio doméstico, se observó un incremento de la demanda de

1. Según esta aproximación, para maximizar las ventajas y reducir los riesgos, los seres humanos deben tomar decisiones racionales en función de las presiones determinadas que les ha tocado vivir. 
empleadas de hogar en distintas partes del planeta -internacionalizacióndentro de los procesos de mercantilización o externalización de la reproducción social. En un mercado global, esta tendencia no era inocua, en palabras de estas autoras, sino que se encontraba en el corazón del debate sobre la reestructuración social de las sociedades occidentales y estaba plenamente vinculada a la aparición de un nuevo «ejército de reserva» determinado por la división global del trabajo.

Esta incorporación laboral se explicaba igualmente con un déficit en el sistema de welfare en los países del sur de Europa, asociado a la falta de infraestructuras de servicios específicas para las familias. De este modo, la inmigración femenina puso sobre el tapete el debate sobre la relación entre género y clase media con los servicios del Estado de bienestar. El análisis de la inmigración femenina reabría, entonces, el análisis sobre la debilidad del Estado de bienestar y su carácter familista (asumir que las familias deben cargar con la responsabilidad del bienestar de sus miembros) en los países de la Europa del Sur, lo cual dio lugar a una débil desmercantilización.

Pero si dicho monográfico fue una referencia en los inicios del desarrollo de la producción científica sobre migración femenina en España ${ }^{2}$, urgía pasar ya a rastrear el tema desde su contemporaneidad, sacando a la luz cómo han ido cambiando los interrogantes y la aproximación a este objeto de estudio desde el año 2000 hasta la actualidad. Algo más de una década después, hemos pasado de la sorpresa y la curiosidad que suscitó el surgimiento de esta migración femenina a la incertidumbre que está provocando, para el conjunto de la sociedad, pensar estas migraciones en el marco de la crisis económica actual. El contexto ha cambiado, en gran medida, en algo más de una década. Desde el periodo de finales de los años noventa, que fue el analizado en el monográfico de PAPERS publicado en el año 2000, caracterizado por las primeras llegadas, pasamos posteriormente a la etapa del boom económico, fundamentada en la ilusión de la burbuja inmobiliaria y que supuso un aumento sin precedentes en la intensidad de las entradas de inmigrantes a España, para desembocar posteriormente en la crisis económica iniciada en 2008, que ha afectado al conjunto de las economías de los países occidentales y, más en concreto, al Viejo Continente y a sus países sureños. Y es que, tras el descalabro económico de los últimos años, el sur de Europa parece seguir reproduciendo un modelo con unas características propias.

En este monográfico, Dolores Juliano nos ofrece una mirada de género a las trayectorias migratorias en época de crisis, sacando a la luz cómo las familias inmigrantes han tenido que diversificar sus estrategias de adaptación a las nuevas situaciones y cómo son las mujeres las que suelen tomar las riendas de estas nuevas estrategias, que abarcan desde el plano laboral (aceptación de empleos por debajo de la cualificación, rebaja en las condiciones de trabajo, incorporación al mercado laboral de miembros del grupo familiar que no

2. En su época, la presentación del monográfico en Barcelona fue sorprendente, ya que asociaciones feministas, asociaciones de inmigrantes y académicas llegaron a abarrotar el aforo. 
estaban ocupados), hasta cambios de residencia, pasando por disminución de gastos que afecta a las remesas, desagrupación familiar y retorno selectivo de las personas del grupo familiar que están sin trabajo. Con ello, se están cerrando las puertas a la movilidad social de las mujeres inmigrantes, a sus posibilidades de trabajar como autónomas, puesto que los recortes sociales caen sobre sus espaldas.

Por su parte, Pedone, Agrela y Gil sacan a la luz cómo la pérdida de empleo y de vivienda ha afectado, de manera específica, a las familias migrantes, y ello se ha traducido en una dificultad para la reagrupación familiar, al no poderse cumplir con los requisitos económicos y de vivienda que exige la legislación. Se constatan igualmente cambios en los proyectos migratorios de las familias latinoamericanas, que incluyen el retorno y la migración a otras ciudades europeas. Estos dos procesos son selectivos, ya que retornan o migran a otros países distintos miembros de la familia en función de las oportunidades y de las nuevas estrategias migratorias que se implantan en el momento de crisis actual. $\mathrm{Si}$, en el monográfico de PAPERS de 2000, nos preguntábamos sobre el impacto que las políticas migratorias estaban teniendo sobre la llegada y la regularización de los inmigrantes, el debate en 2012 está en la reagrupación familiar. De un país de incipiente llegada, centrado en estudiar los flujos de entrada, hemos pasado a reflexionar sobre las políticas de reagrupación familiar. Pedone, Agrela y Gil sustentan que éstas siguen estando diseñadas en clave masculina, puesto que no se consideran a las mujeres como cabeza de familia y reunificadoras, sino como reunificadas y cuidadoras.

Gualda también parte del contexto de crisis para analizar la migración circular de mujeres procedentes de Europa del Este y de África en la agricultura de Huelva. Esta autora analiza cómo, en el campo onubense, se dio un proceso de sustitución de la mano de obra autóctona por inmigrantes en la década de los noventa y cómo este proceso debe entenderse teniendo en cuenta el análisis de género y las políticas de migración circular y codesarrollo. Esta autora estudia, de forma longitudinal, las pautas de contratación en la agricultura onubense, y saca a la luz cómo esta sustitución ha seguido varias fases: la primera, de nacionales por extranjeros varones; la segunda, de varones por mujeres del Este, y la tercera, de mujeres del Este por mujeres africanas. Los efectos de la crisis están trayendo consigo un regreso de los españoles al campo, con lo cual se invierte el proceso de sustitución, de extranjeros por nacionales. La preferencia por mujeres inmigrantes se sustenta en una construcción de la representación por género por parte de los empleadores. Según dicha representación, las extranjeras son supuestamente más sumisas, menos conflictivas, más ordenadas, más limpias y es más fácil convivir con ellas. No obstante, esta representación en tanto a la preferencia no se aplica a la mano de obra autóctona que está sustituyendo actualmente a las mujeres extranjeras en el campo.

Pero el impacto de la crisis tenemos que pensarlo no sólo desde las estrategias que están poniendo en marcha los inmigrantes, y nos surge la siguiente pregunta: «¿Cómo la crisis del welfare en los países del sur de Europa, acelerada 
por los recortes actuales, va a afectar a los arreglos que llevarán a cabo las familias para hacer frente a los trabajos reproductivos?». Si, durante la expansión económica, la debilidad del Estado de bienestar en el sur de Europa se resolvió acudiendo a la mano de obra inmigrante, ¿qué harán las familias españolas cuyos ingresos se han visto mermados y que se encuentran aún más desamparadas por unos estados del bienestar agonizantes? ¿Ocurrirá como en el caso de la fresa? En un contexto de crisis, ¿sustituirá la mano de obra autóctona a la inmigrante en el marco de los servicios domésticos, de cuidado y sexuales? ¿Volverán las mujeres españolas a los hogares? ¿O tal vez sean ellos, sus homólogos varones, ya sean autóctonos o inmigrantes, más afectados por el paro, los que recurran al mandilón y al trapo? Parece necesario realizar un nuevo análisis de género que considere las reestructuraciones familiares, tanto de las familias inmigrantes como de las autóctonas, en el marco de la crisis sobrevenida del Estado de bienestar en el sur de Europa. En efecto, si durante los años noventa nos referíamos fundamentalmente a la crisis de la «reproducción social», hoy en día dicho proceso tenemos que entenderlo igualmente en su articulación con la actual «crisis del capitalismo global», lo cual, como estudiosos de la realidad, nos plantea un doble reto.

Por último, si, ya en el año 2000, el tema de la inmigración femenina destapaba las problemáticas sobre la reformulación de las políticas sociales que trataban con una gran diversidad de poblaciones y nos preguntábamos qué sucedía con un estado de bienestar que tenía que batallar ante un campo de actitudes racistas, es de esperar que el contexto actual de alto desempleo, crisis económica generalizada y cuestionamiento del Estado de bienestar favorezca el debate sobre la percepción de los inmigrantes extranjeros como un problema para la sociedad, tal y como denuncia Juliano, con lo cual podría normalizarse el discurso según el cual los extranjeros suponen una competencia en el uso de las prestaciones sociales. Pero, más allá del cambio de mirada, desde un contexto de llegada a otro de instalación y crisis económica, la producción científica ha variado igualmente el enfoque que se ha ido dando a la temática de género y migración en la última década.

\section{De la trabajadora inmigrante invisible a la familia transnacional como unidad de análisis}

$\mathrm{Si}$, durante los años noventa, una de las preocupaciones principales de la producción científica era sacar a la luz la invisibilidad de las trabajadoras inmigrantes $^{3}$, en la actualidad encontramos otras aproximaciones a esta temática de estudio que alcanzan un mayor protagonismo. La producción científica sobre género y migración se ha desarrollado, en gran medida, en el plano

3. Así se puso de manifiesto, por ejemplo en Barcelona, a principios de los años noventa, cuando se organizaron sesiones sobre el tema «Las mujeres inmigrantes desafían su invisibilidad», promovidas por el Ayuntamiento de la ciudad en partenariado con las mujeres inmigrantes. 
internacional y, en concreto, en España, sacando claramente «del armario» a las mujeres migrantes ${ }^{4}$.

Uno de los giros que se observa en la última década es la aparición de estudios que abordan otros nichos de empleo de las mujeres inmigrantes, más allá del servicio doméstico y la prostitución, trabajos que recogieron fundamentalmente las miradas de los autores que publicaron en el monográfico de PAPERS del año 2000. Así, por ejemplo, en el actual número de esta revista, la aportación de Estrella Gualda analiza la inserción de las mujeres inmigrantes en el trabajo agrícola. Por otro lado, tanto Amelia Sáiz, para el caso de las mujeres chinas en Barcelona, como María Villares, que estudia la migración latinoamericana en Galicia, destacan el papel de las mujeres migrantes en el marco de las estrategias familiares de emprendimiento. La mirada que llevan a cabo estas autoras, además, más allá de subrayar las condiciones de trabajo y de vida de las mujeres inmigrantes, analiza la inserción laboral de las mujeres inmigrantes en su articulación con las estrategias familiares y reproductivas. Además, ponen de relieve cómo, más allá de investigaciones "sobre mujeres», la producción científica está trabajando, cada vez en mayor medida, con un enfoque de género. Así, por ejemplo, María Villares indica cómo los negocios que tienen a la mujer inmigrante a la cabeza no necesariamente conllevan una movilidad social ascendente, puesto que la familia puede apostar por la inserción del hombre en el mercado de trabajo español y hacerlo acorde a su profesión en el país de origen, con lo cual el autoempleo de la mujer constituye una estrategia de refugio, de manera que la estrategia empresarial supondría, en realidad, una "plataforma para la movilidad social del varón", en palabras de esta autora. A la hora de entender las estrategias de movilidad social de las familias de emprendedores migrantes, su análisis también tiene en cuenta a los hijos. Y es que si, en los años noventa, el protagonismo lo tenían las mujeres, en la actualidad, el enfoque se encuentra, en mayor medida, en el estudio de las familias transnacionales. En efecto, el auge en la última década del transnacionalismo, como perspectiva de estudio de las migraciones en el plano internacional, ha llegado a España.

Después de los años noventa, la investigación cambió tímidamente su mirada desde las mujeres inmigrantes hacia las migraciones como un proceso que incluía el análisis de género en la vida transnacional. Así, surgen estudios que sacan a la luz el papel de las redes étnicas, que operan a través del espacio, gracias al casi instantáneo carácter de las comunicaciones, así como de los hogares que tienen un papel activo en las prácticas que se ponen en marcha en el marco del espacio transnacional'5.

4. Así, por ejemplo, en el marco del Congreso sobre las migraciones en España celebrado en A Coruña en el año 2009, la mesa de género y migración (a partir de cuyas contribuciones se gestó esta publicación, como ya hemos señalado) fue la que más propuestas de comunicaciones y ponencias recibió.

5. Véanse, por ejemplo, los primeros trabajos al respecto en las investigaciones en España (Escrivá, 2000; Ribas, 2002). 
Tal y como señala Sonia Parella, citando a Basch et al. (1994), el transnacionalismo supera los «modelos de análisis, focalizados en el estado-nación receptor» (p. 662), e indica cómo los migrantes construyen «campos sociales que vinculan las zonas emisoras con las de destino" (p.662). Esta autora analiza las formas en las cuales la familia transnacional gestiona los vínculos transnacionales y su impacto en las relaciones de género. Su trabajo, que parte de una investigación empírica llevada a cabo con familias de migrantes, tanto en Bolivia como en España, pone de relieve cómo estas transformaciones varían en función de quien haya migrado primero (el varón o la mujer como pionera). Para las mujeres pioneras, aunque su posición laboral se encuentre subordinada (servicio doméstico), se elabora un cierto discurso de "empoderamiento", al constituirse en las principales sustentadoras del grupo familiar.

Amelia Sáiz también ubica su análisis en el marco de las estrategias productivas y reproductivas transnacionales de las familias chinas en España. Para las mujeres procedentes del sur de la provincia meridional y litoral de Zhejiang, el empresariado étnico y las familias transnacionales son los elementos que definen el éxito del proyecto migratorio. Las madres se concentran más en la estrategia productiva que en la reproductiva, sin renunciar a establecer vínculos afectivos con sus hijos e hijas aún en los casos de maternidad transnacional, si bien el transnacionalismo no es la estrategia más común que siguen las personas procedentes de otras regiones, que optan por el localismo, lo cual incluye, en algunos casos, como en el de las mujeres procedentes del noreste, el matrimonio con varones nacionales. Por ello, a veces, se potencia lo transnacional y, en otras ocasiones, lo local, con lo cual se ponen en juego los recursos disponibles (capital social, humano y económico).

Las estrategias matrimoniales de los migrantes son abordadas por Jordi Roca, Yolanda Bodoque y Montserrat Soronellas, que sacan a la luz una temática novedosa en el marco de los estudios de género y migración en España: las migraciones por amor o de mail order brides, y pone de manifiesto, de nuevo, cómo, desde el monográfico de PAPERS del año 2000, la producción científica ha ido otorgando menor protagonismo al mercado de trabajo y mayor a la familia como contexto de análisis de las migraciones femeninas. Para estos autores, este tipo de migración está vehiculada a través de una relación conyugal y se legitima, en el discurso de sus protagonistas, mediante el ideal del amor romántico. Son mujeres que migran sin el apoyo de las redes migratorias, como novias esposas, y que mantienen vínculos con el país de origen que se van debilitando con el paso del tiempo, hasta que llegan incluso a negarse y a sentir un cierto rechazo hacia su cultura de origen, así como hacia su colectivo de origen, como una forma de negación de su condición de inmigrante. Llevan a cabo una incorporación dependiente, ya que delegan su inserción a la sociedad de acogida (jurídica, social y económica) en sus parejas. No obstante, aunque esta incorporación podría verse como un privilegio respecto a sus compatriotas, al tener las mujeres que han migrado por amor el camino «allanado» al llegar a España, en el fondo las convierte en dependientes de su pareja y de su relación con ésta.

Como vemos, en los últimos años, la producción científica ha dado un giro a la hora de estudiar la temática sobre género y migración, puesto que ha pasado 
del protagonismo que tenía la trabajadora inmigrante en los años noventa a las temáticas relacionadas con la familia, la maternidad transnacional y las migraciones por amor. Este giro, si bien da cuenta, en mayor medida, de las dinámicas de género, debe igualmente ser considerado con precaución. En efecto, como señala el texto de Carmen Gregorio para este monográfico, el enfoque centrado en el estudio de la maternidad transnacional que han tenido los trabajos sobre género y migración en los últimos años, puede llegar a reducir esta categoría de análisis al «asumir patrones universales y esenciales que relacionan a todas las mujeres en su capacidad de concebir con el ejercicio de la maternidad» (p. 575). Así, Gregorio propone «la politización de esta categoría, situando la maternidad transnacional en el entramado específico de relaciones de poder en el que se inscriben las prácticas, los significados, las imágenes y los sentimientos, social y culturalmente producidos, incorporando los usos políticos de la misma desde las subjetividades y las identidades que reproducen la noción cultural hegemónica de la maternidad, pero también la resisten. Nuestra atención la pondríamos, de esta forma, en aquellas prácticas y significados maternales (o paternales) desterritorializados, en el contexto de las relaciones de poder que entraña la condición de extranjería, observando cómo se definen y se redefinen identidades y subjetividades de género, parentesco y sexualidad» (p. 575). Por otro lado, esta autora nos hace ver cómo centrarse en denunciar las desigualdades entre mujeres del Norte y del Sur partiendo del concepto de «cadenas mundiales de afecto y asistencia» debería igualmente reconsiderarse, puesto que «situar el problema en el supuesto conflicto entre mujeres hace un flaco favor a la empresa feminista» (p. 577). De esta manera, es necesario «politizar los cuidados sacándolos del espacio "privado" del hogar y de su contenido naturalizado en su asociación con lo femenino, para situarlos en el centro de procesos políticos e históricos que construyen cuerpos generizados, sexualizados, racializados, etnizados y desterritorializados en su relación con el cuidado» (p. 577). Así, esta autora, con el objetivo de superar en las propuestas conceptuales «las dicotomías entre producción y reproducción, público y privado, hombre y mujer, sistema de género de la sociedad de origen y sistema de género de la sociedad receptora, pasividad y agencia» (p. 585), de tal manera que se pueda mostrar como «se construye el género, pero también la raza, la etnia, el parentesco, la cultura y otras diferenciaciones sociales que son asumidas desde nuestros marcos teóricos y espistemológicos como realidades preexistentes» (p. 585).

En síntesis, nos encontramos de lleno en otra etapa. Una etapa marcada por un nuevo contexto socioeconómico de crisis que ha afectado, sobre todo, al sector de la construcción y, en concreto, a los varones inmigrantes. Una etapa condicionada por las políticas de retorno impulsadas por el Gobierno español, pero, igualmente, una etapa mediatizada por un cambio de mirada al estudio de las migraciones internacionales por parte de los científicos sociales. Por unas nuevas «lentes» que ya no priman tanto el estudio de las trabajadoras migrantes, en el marco de déficit en el sistema de welfare, sino el análisis de las dinámicas familiares transnacionales, con un enfoque de género. 


\section{Agradecimientos}

Este volumen no hubiese salido a la luz sin el apoyo de la profesora Carlota Solé, quien siempre creyó que el estudio de las migraciones y el género era un tema central de la sociología contemporánea. Somos igualmente deudoras del inestimable trabajo de las autoras y de los autores, así como del esfuerzo editorial del Servei de Publicacions de la UAB.

\section{Referencias bibliográficas}

BASCH, Lina; Glick SChiller, Nina y Szanton BlanC, Cristina (1994). Nations unbound: Transnational projects, postcolonial predicaments and deterritorialized nation-states. Pensilvania: Gordon and Breach Science Publishers.

Catarino, Christine y Oso, Laura (2000). «La inmigración femenina en España y Portugal: hacia una etnización del servicio doméstico y de las empresas de limpieza». Revista Papers. Monográfico «Inmigración femenina en el sur de Europa», 60, 183-207.

Colectivo IOÉ (2001). Mujer, inmigración y trabajo. Madrid: Ministerio de Trabajo y Asuntos Sociales.

ESCRIVÁ, Ángeles (2000). «:Empleadas de por vida?: Peruanas en el servicio doméstico de Barcelona». Revista Papers. Monográfico «Inmigración femenina en el sur de Europa», 60, 327-342.

- (2003). «Inmigrantes peruanas en España: Conquistando el espacio laboral extradoméstico». Revista Internacional de Sociología, 36, 59-83.

GREGORIO, Carmen (1998). Migración femenina: Su impacto en las relaciones de género. Madrid: Narcea.

Herranz, Yolanda (1996). Formas de incorporación laboral de la inmigración latinoamericana en Madrid: Importancia del contexto de recepción. Tesis doctoral. Universidad Autónoma de Madrid. Departamento de Sociología y Antropología Social. Facultad de Ciencias Económicas y Empresariales.

KING, Russell y ZonTINI, Elisabetta (2000). "The role of gender in the South European immigration model». Revista Papers. Monográfico «Inmigración femenina en el sur de Europa», 60, 35-52.

Oso, Laura (1998). La migración hacia España de mujeres jefas de hogar. Madrid: Instituto de la Mujer. Ministerio de Trabajo y Asuntos Sociales. Serie Estudios; 52.

Parella, Sonia (2003). Mujer, inmigrante y trabajadora, la triple discriminación. Barcelona: Anthropos.

RAMíREZ, Ángeles (1998). Migraciones, género e Islam: Mujeres marroquies en España. Madrid: Agencia Española de Cooperación Internacional.

Ribas MATEOS, Natalia (1999). La presencia de la inmigración femenina: Un recorrido por Filipinas, Gambia y Marruecos en Cataluña. Barcelona: Icaria-Antrazyt.

- (ed.) (2000). «Inmigración femenina en el sur de Europa». Revista Papers, 60.

- (2002). «Estrategias transnacionales: Una pregunta sobre las migraciones femeninas en España». Arxius, 5, 69-92.

SolÉ, Carlota (1994). La mujer inmigrante. Madrid: Instituto de la Mujer. 